Article

\title{
Design and Characterization of a Novel Tool for the Antigenic Enrichment of Actinobacillus pleuropneumoniae Outer Membrane
}

\author{
Fabio Antenucci ${ }^{1}\left(\mathbb{D}\right.$, Armen Ovsepian $^{1}{ }^{1}$, Agnieszka Wrobel ${ }^{2}$, Hanne Cecilie Winther-Larsen ${ }^{2}$ \\ and Anders Miki Bojesen ${ }^{1, *(1)}$ \\ 1 Department of Veterinary and Animal Sciences, University of Copenhagen, \\ Stigbøjlen 4, 1870 Frederiksberg C, Copenhagen, Denmark; fante@sund.ku.dk (F.A.); \\ armovse@hotmail.com (A.O.) \\ 2 Section of Pharmaceutical Biosciences, Centre of Integrative Microbial Evolution, Department of Pharmacy, \\ University of Oslo, Sem Sælandsvei 3, 0316 Oslo, Norway; agnieszka_wrobel1@wp.pl (A.W.); \\ h.c.winther-larsen@farmasi.uio.no (H.C.W.-L.) \\ * Correspondence: miki@sund.ku.dk
}

Received: 16 November 2020; Accepted: 30 November 2020; Published: 2 December 2020

\begin{abstract}
Production and isolation of recombinant proteins are costly and work-intensive processes, especially in immunology when tens or hundreds of potential immunogens need to be purified for testing. Here we propose an alternative method for fast screening of immunogen candidates, based on genetic engineering of recombinant bacterial strains able to express and expose selected antigens on their outer membrane. In Actinobacillus pleuropneumoniae, a Gram-negative porcine pathogen responsible for extensive economic losses worldwide, we identified a conserved general secretion pathway (GSP) domain in the N-terminal part of the outer membrane protein ApfA (ApfA stem: $\left.\operatorname{Apf}_{s}\right)$. ApfA $A_{s}$ was used as an outer membrane anchor, to which potential immunogens can be attached. To enable confirmation of correct positioning, $\mathrm{ApfA}_{\mathrm{s}}$, was cloned in combination with the modified acyl carrier protein $(\mathrm{ACP})$ fluorescent tag $\mathrm{ACP}$ mini $\left(\mathrm{ACP}_{\mathrm{m}}\right)$ and the putative immunogen VacJ. The chimeric construct was inserted in the $\mathrm{pMK}$-express vector, subsequently transformed into A. pleuropneumoniae for expression. Flow cytometry, fluorescence imaging and mass spectrometry analysis were employed to demonstrate that the outer membrane of the transformed strain was enriched with the chimeric $\mathrm{ApfA}_{\mathrm{s}}-\mathrm{ACP}_{\mathrm{m}}$-VacJ antigen. Our results confirmed correct positioning of the chimeric $\mathrm{ApfA}_{\mathrm{s}}-\mathrm{ACP}_{\mathrm{m}}$-VacJ antigen and supported this system's potential as platform technology enabling antigenic enrichment of the outer membrane of A. pleuropneumoniae.
\end{abstract}

Keywords: Actinobacillus pleuropneumoniae; vaccine development; immunogen screening; antigenic enrichment

\section{Introduction}

Since its inception, genetic engineering has enabled protein expression and purification in a variety of microorganisms [1,2]. One of the possible applications of this technique is the expression of recombinant antigens for vaccine development, defined as immunogens. In the case of bacterial vaccines, these antigens are often proteins located on the outermost surface of the bacteria [3,4].

The identification of useful protein immunogens is not an easy task, despite the contribution offered by the advent of bioinformatic screening tools for these purposes [5-7]. One of the main challenges is the identification of conserved proteins able to offer protection against ideally all known variants of the bacterial species/types targeted [8,9]. Even when conserved candidates are successfully identified, prediction tools offer disappointingly little help regarding the actual potential of these 
proteins for vaccine development, often leading to a high degree of negative results when tested in vivo $[10,11]$. This in turn increases the number of candidates that need to be expressed and tested and hence the need for expression systems requiring less resources.

One option to account for this need is represented by antigenic enrichment, where the presence of a desired immunogen in a specific subcellular compartment, such as the bacterial outer membrane (OM), is increased [12,13]. Using that approach it is possible to engineer bacterial clones by heterologous gene transfer (HGT) to express recombinant proteins on the OM. The clones can then be administered in vivo to verify the protective potential of the candidate immunogens. This eliminates the need of isolating and purifying each of the proteins to be tested, thus reducing considerably the costs and workload needed [14]. To achieve targeted enrichment, the subcellular localization of the recombinant protein expressed often needs to be specifically engineered by introducing a short sequence of amino acids at the proteins N-terminal, defined as signal peptide [15]. It must be noted though that the presence of a correct signal peptide is often not sufficient to guarantee the correct subcellular localization of a recombinant protein and additional parameters need to be considered during the engineering process. This is particularly true in the case of secreted or membrane-bound immunogens, where incorrect folding, surface charge and cleavage can prevent access to the channels responsible for trans-membrane translocation, hindering the whole process as a result [16].

Once engineered, the recombinant protein is then expressed in the host organism of choice, where its correct subcellular localization needs to be confirmed. This is usually accomplished by using different reporter systems. One such system involves the utilization of monoclonal antibodies for indirect immunodetection [17]. The main disadvantage of this system is that in many instances specific antibodies binding the expressed protein are not available. This is especially relevant for proteins that have not yet been fully described, as is often the case for putative vaccine candidates. Alternatively, recombinant proteins can be labelled by using a wide array of fusion tags [18], facilitating not only detection but also increasing solubility and levels of expression [14]. Autofluorescent or immunogenic tags can be included in the sequence of the recombinant protein to allow detection and quantification but these tags tend to be rather large, thus interfering with the protein exportation through bacterial membranes and may significantly alter its antigenicity $[14,19]$. Both these problems can be addressed by using smaller tags for indirect fluorescent detection, namely tags recognized by specific enzymes able to mediate the post-translational labelling of the recombinant protein with a fluorescent substrate [20].

An additional factor to consider is how to ensure the stable integration of the recombinant protein into the OM. Most antigens of interest possess lipophilic domains and are naturally embedded into the outer layer of the OM, whereas others are secreted and require modifications to ensure OM localization. OM domains can be identified in several bacterial species by analyzing the mechanisms of transport and sequence of well-characterized OM determinants, such as fimbriae or lipoproteins $[7,21,22]$. Once identified, these domains can be included into the open reading frame (ORF) of a recombinant protein by polymerase chain reaction (PCR)-based tagging [23], enhancing the chances of its stable integration on the outer layer of the OM when exported [24].

Resuming, there are four crucial features that need to be included in a recombinant immunogen targeted for native OM localization: (i) a signal peptide for OM localization; (ii) an OM domain to anchor the protein to the bacterial surface; (iii) a detection domain for localization and quantification; (iv) a domain corresponding to the actual immunogen to be tested, either as a complete or partial protein.

Here we describe the development of a novel platform technology according to these features that allows selective antigen-enrichment of the OM of A. pleuropneumoniae, a Gram-negative bacterium of great veterinary interest for which increasingly effective vaccines are needed [25-27]. Main aim of this study was to provide an initial assessment of the feasibility of antigenic enrichment of A. pleuropneumoniae $\mathrm{OM}$ in a quantifiable and cost-effective manner. 


\section{Results}

\subsection{ApfAs is a Conserved OM Domain}

Analysis by PANTHER ${ }^{\mathrm{TM}}$ identified amino acid residues $14-67$ of the ApfA protein $\left(\mathrm{ApfA}_{\mathrm{s}}\right)$ as a conserved domain of general secretion pathway (GSP) proteins (PANTHER ID: PTHR30093). Further in silico analysis corroborated the inferred OM localization of ApfA (PSORTb 3.0), also supported by the prediction of a cytoplasmic domain at the N-terminal of ApfA (residues 1-11; PHOBIUS) and the folding of residues 16-66 to form a hydrophilic alpha-helix (I-TASSER).

Analysis by protein BLAST (non-redundant protein sequences database) revealed a significant homology of the ApfAs domain with peptidase-dependent pilins from several Enterobacteriaceae species. The following entry is reported here as representative of the analysis: MULTISPECIES: prepilin peptidase-dependent pilin [Enterobacteriaceae] (NCBI accession number: WP_000360918.1; $82 \%$ query coverage, $51,79 \%$ identity).

No relevant homology was detected between the $\mathrm{ApfA}_{\mathrm{s}}$ domain and the following E. coli proteins_OmpA (GenBank accession number: NP_415477.1); LamB (GenBank accession number: VWQ00259.1); PhoE (GenBank accession number: VWQ01102.1); FimH (GenBank accession number: NP_418740.1); PapA (GenBank accession number: AAL67417.1); Flagellin (GenBank accession number: WP_001556318.1); AidA (GenBank accession number: ADD91708.1).

\section{2. $A p f A_{s}-A C P_{m}$-Vacj is Expressed and Localized on A. pleuropneumoniae $O M$}

Fluorescence imaging indicated that $\mathrm{pMK} \_a p f a_{\mathrm{s}}-\mathrm{ACP}_{\mathrm{m}}-v a c J$ cells emitted higher fluorescent signal as compared to the wild type (wt) (Figure 1) when AcpS and fluorescent coenzyme A (CoA) are provided in solution. Under similar conditions, flow cytometry analysis detected a significant increase $(p<0.01)$ between $30-60 \%$ of the geometric mean of the emitted green fluorescence signal from the pMK_apfa $a_{\mathrm{s}}-\mathrm{ACP}_{\mathrm{m}}$-vacj cells when compared to the wt (Figure 2).

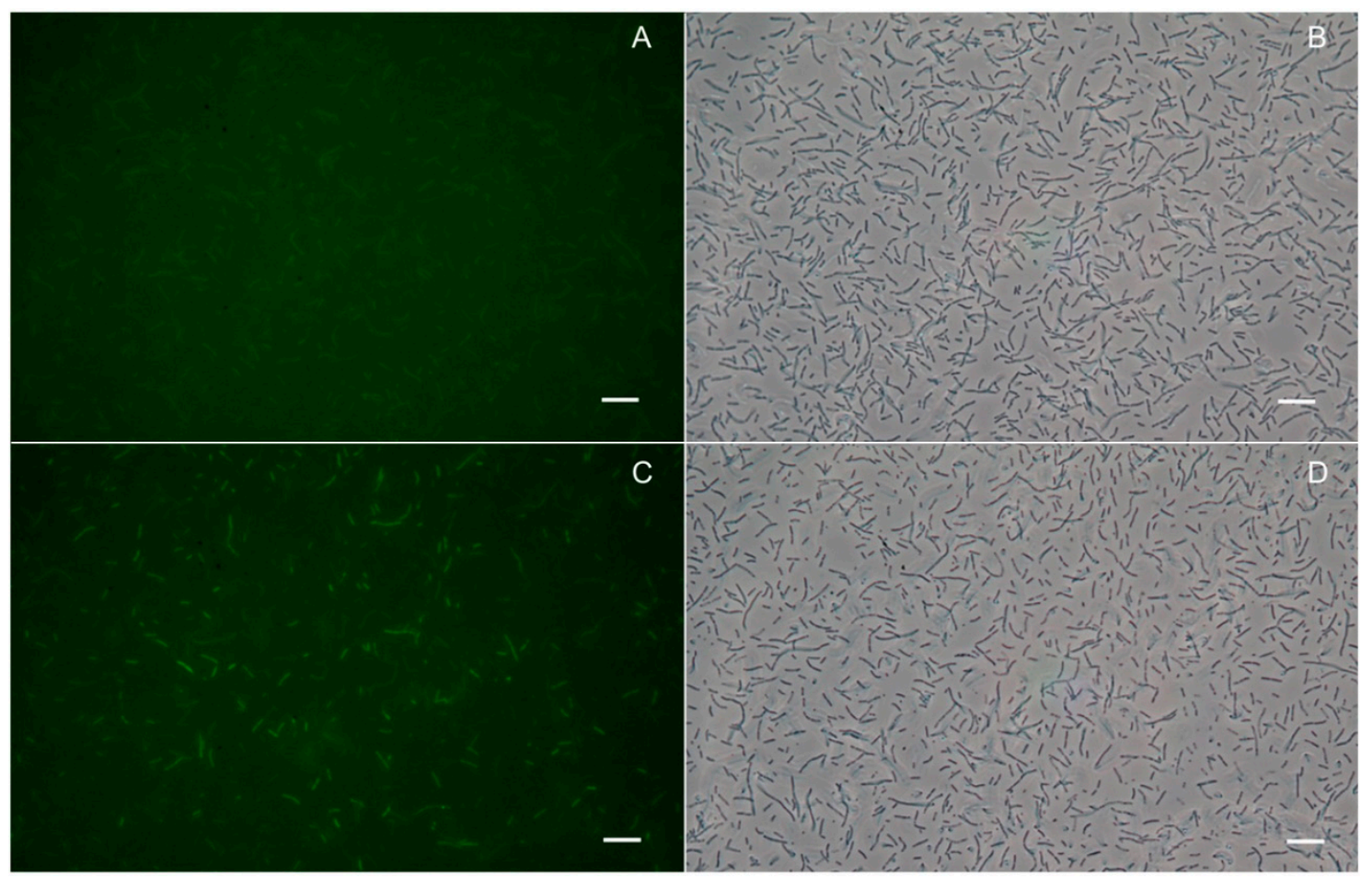

Figure 1. Fluorescence and non-fluorescence phase contrast microscopy images of A. pleuropneumoniae wild type (wt) (A and $\mathbf{B}$ respectively) and $\mathrm{pMK}$ a $a f a_{\mathrm{s}}-\mathrm{ACP}_{\mathrm{m}}-v a c J$ cells ( $\mathbf{C}$ and $\mathbf{D}$ respectively) after staining with fluorescent CoA 488. Scale bars represent $10 \mu \mathrm{m}$. Results presented are representative of three independent experiments. 


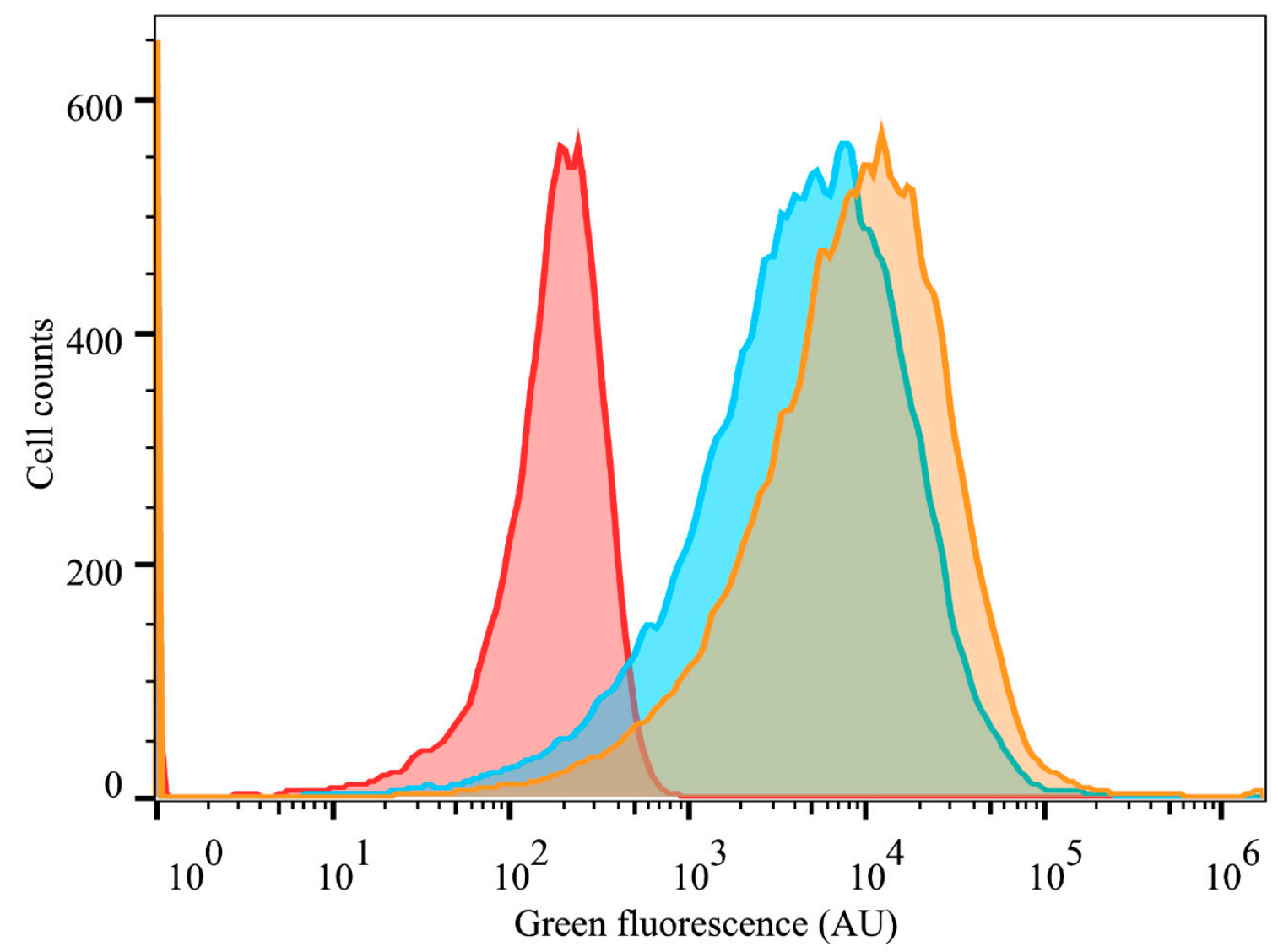

\begin{tabular}{|l|l|l|}
\hline \multicolumn{1}{|c|}{ sample name } & Geometric mean \\
\hline$\square$ & pMK_apfAs-ACPm-vacJ stained & 8155 \\
\hline & WT stained & 5116 \\
\hline$\square$ & Unstained cells & 724 \\
\hline
\end{tabular}

Figure 2. Fluorescence levels of $A$. pleuropneumoniae wt (blue) and $\mathrm{pMK}$ apfa $a_{\mathrm{s}}-\mathrm{ACP}_{\mathrm{m}}$-vacJ cells (orange) after staining with fluorescent CoA 488 and analysis by flow cytometry. The histograms show the distribution of green fluorescence levels in the populations of each strain. The histogram of unstained cells of A. pleuropneumoniae wt is also presented (red). The geometric mean of the fluorescent cells of each sample is shown below the figure. Results presented are representative of three independent experiments. AU: arbitrary units. WT: wild type.

Sodium dodecyl sulfate polyacrylamide gel electrophoresis (SDS-PAGE) analysis showed no qualitatively detectable differences in banding patterns of the $\mathrm{OM}$ fractions of $\mathrm{pMK} \_a p f a_{\mathrm{s}}-\mathrm{ACP}_{\mathrm{m}}-v a c J$ and wt cells (Figure 3). MS analysis of the OM fraction of pMK_apfa $a_{\mathrm{s}}-\mathrm{ACP}_{\mathrm{m}}$-vacj cells assigned 49 total spectra (11 exclusive unique peptides, 19 exclusive unique spectra) to VacJ, as compared to 35 total spectra (10 exclusive unique peptides, 17 exclusive unique spectra) assigned to VacJ for the OM fraction of wt cells (Table S1), indicating that the concentration of VacJ was about $29 \%$ higher for the pMK_apfa $a_{\mathrm{s}}-\mathrm{ACP}_{\mathrm{m}}$-vacj OM fraction as compared to the wt. On the contrary, no significant differences in total spectra assigned to ApfA were detected between OM fractions of $\mathrm{pMK}_{-} a p f a_{\mathrm{s}}-\mathrm{ACP}_{\mathrm{m}}-v a c J$ and wt strains (Table S1). No spectra were assigned to the $\mathrm{ACP}_{\mathrm{m}}$ tag in the $\mathrm{OM}$ fractions of both pMK_apfa $a_{\mathrm{s}}-\mathrm{ACP}_{\mathrm{m}}-v a c J$ and wt strains (Table S1). 


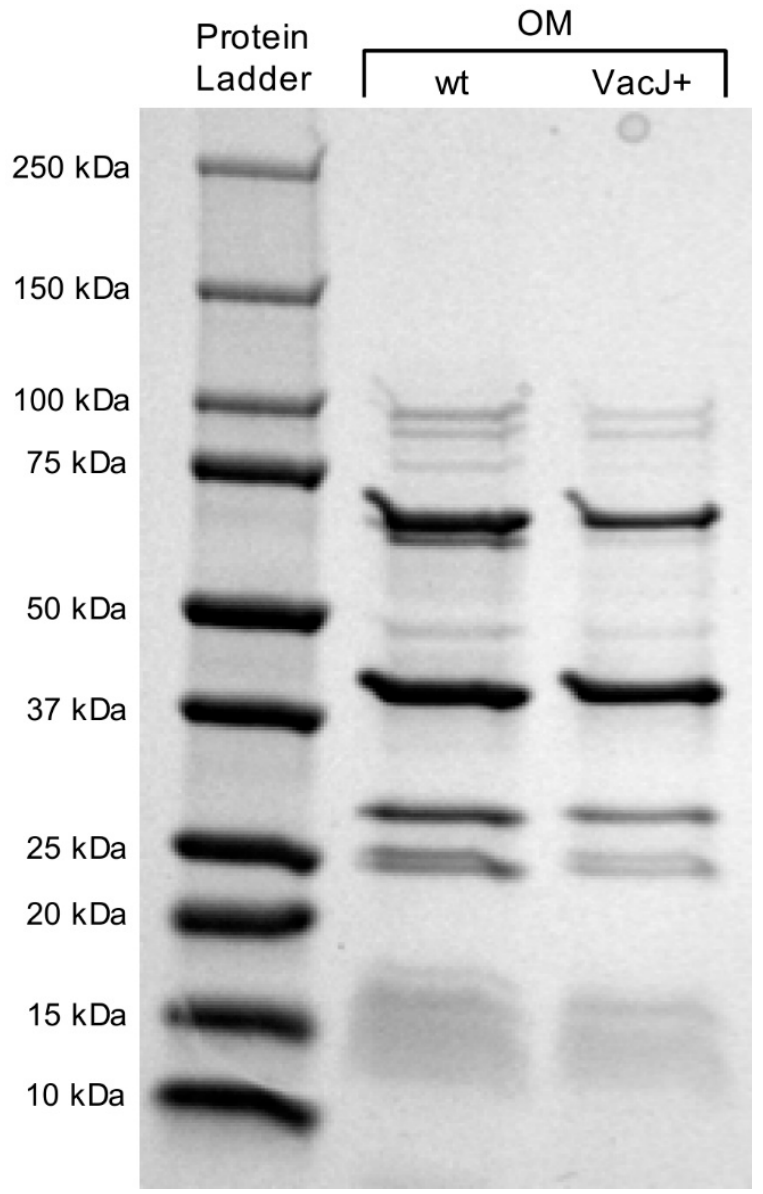

Figure 3. SDS-PAGE (sodium dodecyl sulfate polyacrylamide gel electrophoresis) analysis of outer membrane (OM) fractions of A. pleuropneumoniae serotype $8 \mathrm{MIDG} 2331 \mathrm{wt}$ and pMK_apfa $a_{\mathrm{s}}-\mathrm{ACP}_{\mathrm{m}}$-vacJ cells. wt: wild type; VacJ+: $\mathrm{pMK} \_a p f a_{\mathrm{s}}-\mathrm{ACP}_{\mathrm{m}}$-vacJ; Protein ladder: Precision Plus Protein ${ }^{\mathrm{TM}}$ Dual Color Standards (Bio-Rad). The molecular weight of protein ladder bands is reported for reference.

\section{Discussion}

The in silico design of the $\mathrm{ApfA}_{\mathrm{s}}-\mathrm{ACP}_{\mathrm{m}}$-VacJ chimera was a multi-step process that can be divided in the identification of the three domains comprising the final protein: (i) an OM anchoring domain $\left(\mathrm{ApfA}_{\mathrm{s}}\right)$; (ii) a domain for post-expression localization and quantification of the chimeric antigen; (iii) a putative immunogen to be tested (VacJ).

(i) ApfA is a fimbrial subunit protein involved in the initial stages of colonization of A. pleuropneumoniae whose role in pathogenesis and potential as an immunogen have previously been investigated [28-33]. As a well-characterized fimbrial protein, we hypothesized that ApfA would be exposed and anchored on A. pleuropneumoniae OM. This was subsequently supported by the in silico analysis performed in the current study, leading us to conclude that the $\mathrm{ApfA}_{\mathrm{s}}$ domain would likely fold into an OM "stem" (hence the "S" in $\mathrm{ApfA}_{\mathrm{s}}$ ) and could thus act as an anchoring domain within a chimeric open reading frame (ORF) designed to expose selected antigens on the surface of A. pleuropneumoniae.

Due to the high conservation across Gram-negative bacteria of the general secretion pathway (GSP) domain identified in the ApfA sequence, we also hypothesized that a delivery system based on ApfA could offer a broader applicability and be employed for the selective OM enrichment of bacteria other than A. pleuropneumoniae. Additionally, the lack of significant homology between the $\mathrm{ApfA}_{\mathrm{s}}$ domain and a selection of other proteins previously employed in membrane display strategies (OM proteins OmpA, LamB and PhoE; fimbrial and flagellar proteins FimH, PapA and flagellin; 
Autotransporter protein AidA) [34-36] supported the novelty of the strategy proposed. Apf $\mathrm{A}_{\mathrm{s}}$ was thus selected as a suitable OM anchor.

(ii) The next feature of the chimeric antigen to be addressed was the need for post-expression localization and quantification. For this purpose, we relied on a method known as covalent labelling. This technique is based on the ability of certain enzymes to recognize specific peptide tags, catalyzing then the covalent transfer of substrates on the tagged protein [37]. The main reason behind the selection of this technique over autofluorescent-based detection here was the comparative advantage offered by covalent labelling when designing membrane-bound recombinant proteins. For covalent labelling in fact, both the enzyme and the substrate need to be externally supplied by the user. Contrary to autofluorescent-based detection, this ensures that only the exported fraction of the recombinant protein will be detected, as the labelling enzyme in particular will not be able to access intracellular compartments.

The selected tag for covalent labelling was the ACP-tag, a small tag recognized by the acyl carrier protein synthase (AcpS) for the covalent transfer of fluorescent derivatives of coenzyme A (CoA). [38]. Albeit relatively small, the full length of the ACP-tag is 77 amino acids, resulting in a 9-kDa domain. The sheer size of the ACP tag clearly hampers its usefulness for post-expression quantification and localization of recombinant immunogens, due to the likely alteration of the antigenic profile of the immunogen that the inclusion of such large domain would induce. Interestingly, it has been demonstrated that just eight residues of the ACP-tag are required for labelling by AcpS [39]. This shortened ACP-tag, defined here as $\mathrm{ACP}-\mathrm{mini}\left(\mathrm{ACP}_{\mathrm{m}}\right)$, presents two advantages over the full ACP-tag, both related to its smaller size. First and foremost, a domain of just eight amino acids is far less likely to affect trafficking and antigenicity of the engineered protein it is included in [20]. Secondly, the 24 nucleotides that encode for the $\mathrm{ACP}_{\mathrm{m}}$ tag can be easily included as $5^{\prime}$ overhangs in the primers used during cloning, reducing the number of inserts needed to be stitched together for the creation of the recombinant ORF, thus increasing transformation efficiency. These considerations led us to select the $\mathrm{ACP}_{\mathrm{m}}$ tag as a detection domain for the chimeric antigen discussed here.

(iii) The last step of the design consisted of identifying a native A. pleuropneumoniae immunogen to be tested. Ideally, this immunogen should possess the following characteristics: (1) proven immunogenicity, in order to provide immunological relevance to the chimera; (2) predicted OM subcellular localization, to increase the chances of seamless transport of the chimera through cellular membranes; (3) lack of toxicity, allowing high level of expression of the chimera in the host strain.

Protein homologs belonging to the VacJ lipoprotein family are part of the conserved VacJ/Yrb ATP-binding cassette $(\mathrm{ABC})$ transport system involved in phospholipid translocation through the OM [40]. We previously demonstrated that the VacJ-like homolog expressed in A. pleuropneumoniae strains presents a predicted OM subcellular localization, is easily expressible as recombinant protein and is highly immunogenic when administered in vivo as part of an immunization regime [32,33]. For these reasons, VacJ was selected as putative immunogen to be included in the chimera design described in this study.

Quantification by fluorescent labelling indicated that the $\mathrm{ApfA}_{\mathrm{s}}-\mathrm{ACP}_{\mathrm{m}}-\mathrm{Vacj}$ chimera is expressed and localized on the $\mathrm{OM}$ of $\mathrm{pMK} \_a p f a_{\mathrm{s}}-\mathrm{ACP}_{\mathrm{m}}-v a c J$ cells. When using a fluorescent $\mathrm{CoA}$-based labelling system though it is important to keep in mind that Acetyl-CoA is a major component of several metabolic pathways in bacteria, such as the biosynthesis of fatty acids and phospholipids. Accordingly, many Gram-negative bacteria actively import CoA to the cytoplasm and possess a native acetyl-transferase activity due to the expression of a homolog of the recombinant AcpS enzyme used for ACP-tag labelling [38]. This represents one of the main disadvantages when using ACP-tag labelling in bacterial strains, including A. pleuropneumoniae, as the accurate estimation of the expression level of the tagged recombinant protein can be skewed by a high background due to: (i) translocation to the cytoplasm of the fluorescent CoA substrate administered extracellularly during labelling; (ii) Incorporation of fluorescent CoA substrate into untagged proteins by native AcpS proteins. Both these processes represent a central part of the normal metabolism of unmodified bacterial strains and thus an inherent 
shortcoming of this labelling system. To overcome this problem, the ACP tag may need to be replaced with similar tags and fluorescent derivatives [41] in order to achieve a more stringent quantification of the levels of expression of the recombinant chimera.

To overcome this potential issue, protein assays were performed on the $\mathrm{OM}$ fractions of pMK_apfa $a_{\mathrm{s}}-\mathrm{ACP}_{\mathrm{m}}-v a c J$ and wt cells to verify the actual concentration of the $\mathrm{ACP}_{\mathrm{m}}$-VacJ chimera. Although SDS-PAGE showed no qualitatively detectable differences in banding patterns of the OM fractions of pMK_apfa $a_{\mathrm{s}}-\mathrm{ACP} \mathrm{m}_{\mathrm{m}}$-vacJ and wt cells, MS analysis suggested an increase of about $29 \%$ in the concentration of Vacj for the $\mathrm{pMK} \_a p f a_{\mathrm{s}}-\mathrm{ACP}_{\mathrm{m}}-\mathrm{vacj} \mathrm{OM}$ fraction as compared to the wt. This confirmed the level of enrichment of the $\mathrm{ACP}_{\mathrm{m}}$-VacJ chimera previously observed by fluorescent labelling. Interestingly, no significant differences in ApfA concentration were detected between OM fractions of pMK_apfa $a_{\mathrm{s}}-\mathrm{ACP}_{\mathrm{m}}-v a c J$ and wt strains, possibly due to the technical challenge posed by extraction and purification of trans-membrane protein domains such as the $\mathrm{N}$-terminal of $\mathrm{ApfA}_{\mathrm{s}}$ [42]. As expected, the small size of the $\mathrm{ACP}_{\mathrm{m}}$ tag prevented its identification by the MS methodology employed in this study.

\section{Materials and Methods}

\subsection{In Silico Functional Prediction of ApfA Domains}

A list of the genetic sequences, vectors and primers used in this study is provided in Table 1. The protein ApfA was selected for the identification of OM domains due to its well-characterized OM localization. The ApfA peptide sequence was analyzed by different online tools for functional prediction: (i) PANTHER ${ }^{\mathrm{TM}}$ scoring [43,44]; (ii) PHOBIUS [45]; (iii) I-TASSER [46]; (iv) PSORTb [7]. Nucleotides 1-205 from the apfA open reading frame were selected as "stem" domain (apf $A_{\mathrm{s}}$ ) for $\mathrm{OM}$ anchoring of the chimeric antigen. The amino acid sequence of the $a p f A_{\mathrm{s}}$ domain was analyzed by protein BLAST [47] to assess inter-species homology. Standard parameters were used unless otherwise stated.

Table 1. Sequences and primers used in this study.

\begin{tabular}{|c|c|c|}
\hline Denomination & Sequence $\left(5^{\prime}->3^{\prime}\right)$ /Accession Number (GenBank) & Function \\
\hline App 5b L20 apfA gene & СР000569.1 & apfA ORF \\
\hline App $5 \mathrm{~b}$ L20 apf $A_{\mathrm{s}}$ locus & $\begin{array}{l}\text { Nucleotides 1-205 from } \\
\text { A. pleuropneumoniae } 5 \mathrm{~b} \text { L20 apfA }\end{array}$ & apfA stem \\
\hline App 5b L20 vacJ gene & СР000569.1 & vacj ORF \\
\hline $\mathrm{ACP}_{\mathrm{m}}$ tag & GATTCGCTTGATATGCTGGAGTGG & Indirect detection of expression \\
\hline pMK-express vector & GQ334690.1 & Naïve expression vector \\
\hline $\begin{array}{l}\text { apfA Fwd } \\
\text { apfA Rev }\end{array}$ & $\begin{array}{l}\text { CATcAGTAAAGGAGAATGCAgAAgCTAAGTCTTATTCGA } \\
\text { CCAGCATATCAAGCGAATCTCCGGTGTTATATATGCAGATCTCG }\end{array}$ & apf $A$ amplification \\
\hline $\begin{array}{l}\text { vacj Fwd } \\
\text { vacj Rev }\end{array}$ & $\begin{array}{l}\text { GCTTGATATGCTGGAGTGGAAgTTAAAgCAATTAAGgTTAGTAGCC } \\
\text { CAATTCACTGGCCGTTCTGCTCCTTTGCCCTATCC }\end{array}$ & vacJ amplification \\
\hline $\begin{array}{l}\text { pMK Rev } \\
\text { pMK Fwd }\end{array}$ & $\begin{array}{l}\text { ACTTAGcTTcTGCATTCTCCTTTACTgATGGTCAATTCTC } \\
\text { GGGCAAAGGAGCAGAACGGCCAGTGAATTGTAATACG }\end{array}$ & pMK vector linearization \\
\hline
\end{tabular}

Lower case letters indicate nucleotides modified from the target sequence in order to reduce the formation of primer secondary structures or satisfy the parameters for In-Fusion cloning.

\subsection{Design of the apf $A_{s}-A C P_{m}$-vacj Chimera}

$a p f A_{\mathrm{s}}, \mathrm{ACP}$ and vacJ protein sequences were combined into the chimeric apfa $a_{\mathrm{s}}-\mathrm{ACP}_{\mathrm{m}}$-vacJ ORF using the following rationale ( $\mathrm{N}$ to $\mathrm{C}$-terminal): $\mathrm{ApfA}_{\mathrm{s}}$ as $\mathrm{OM}$ anchoring domain; $\mathrm{ACP}_{\mathrm{m}}$ as reporter tag; VacJ as putative immunogen (Figure 4). 


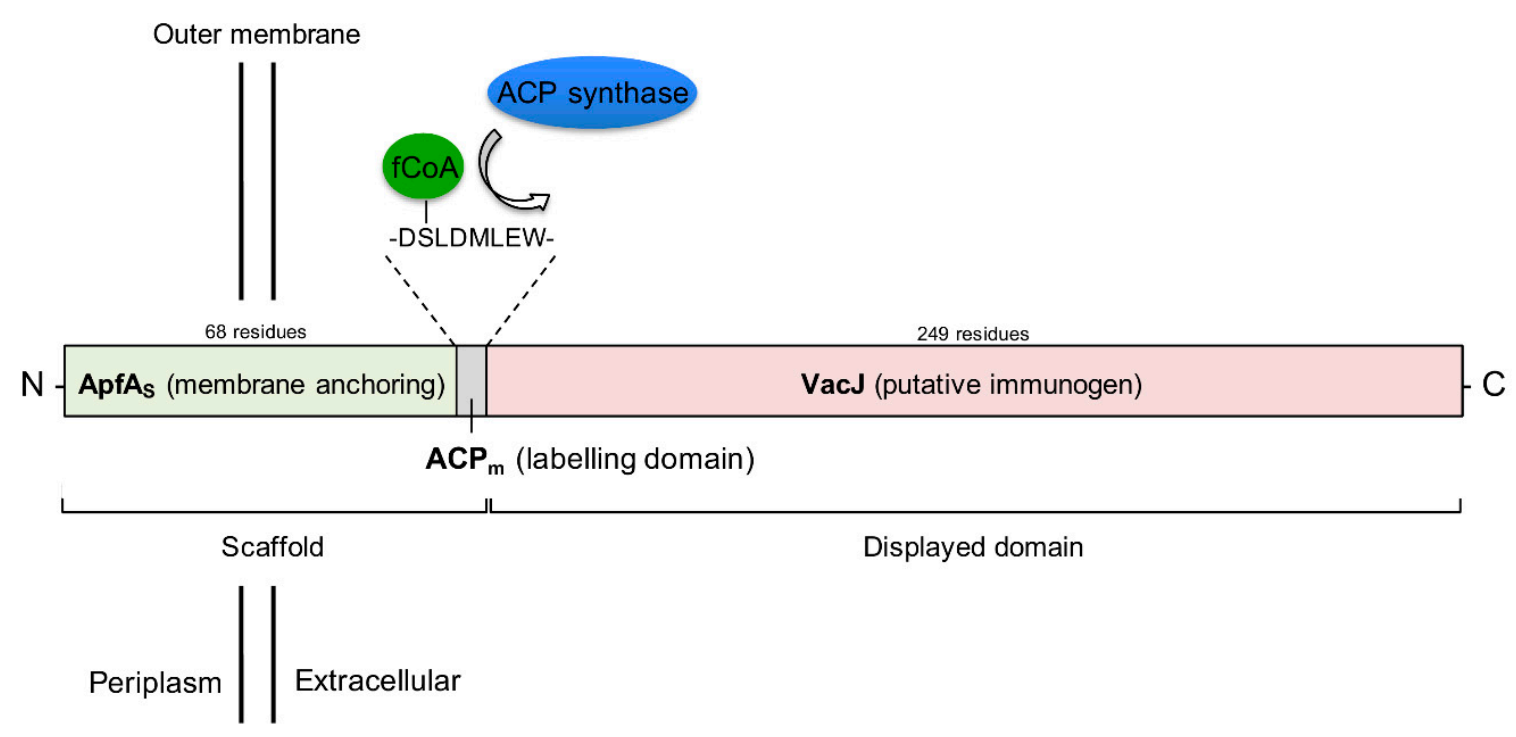

Figure 4. Functional outline of structure and predicted subcellular localization of the $a p f a_{\mathrm{s}}-\mathrm{ACP} \mathrm{m}_{\mathrm{m}}-v a c J$ chimera. $\mathrm{ACP}_{\mathrm{m}}$ amino acid sequence and $\mathrm{ACP}$ synthase target site on $\mathrm{ACP}_{\mathrm{m}}$ are also shown. Relative domain size is represented to scale. ApfA $A_{s}$ ApfA stem domain; $\mathrm{ACP}_{\mathrm{m}}$ : $\mathrm{ACP}-\mathrm{mini}$ tag; VacJ: putative immunogen; fCoA: fluorescent Acetyl-Coenzyme A. N-: N-terminal; C-: C-terminal.

\subsection{Construction and Transfer of the apf $A_{s}-A C P_{m}$-vacJ Expression Vector}

$a p f A_{\mathrm{s}}$ and vacj nucleotide sequences (444 and 747 nucleotides respectively) were amplified from genomic DNA using AccuPrime Taq DNA high-fidelity Polymerase (ThermoFisher Scientific, Waltham, MA, USA). The pMK-express vector was linearized by reverse amplification using the same polymerase, in order to replace the native GFPmut3 gene with the recombinant $a p f a_{\mathrm{s}}-\mathrm{ACP}_{\mathrm{m}}-v a c J$ ORF by ligation-independent cloning (LIC). apf $A_{\mathrm{S}}$ and vacJ amplicons were joined with the linearized vector by three-point ligation-independent cloning, according to the In-Fusion protocol (Clontech Laboratories, Mountain View, CA, USA). The sequence of the $\mathrm{ACP}_{\mathrm{m}}$ tag was introduced in frame between apf $A_{\mathrm{s}}$ and vacJ sequences by PCR-based tagging, including the 24 nucleotides of the tag into the $15 \mathrm{bp}$ overhangs of apfA-Rev and vacJ-Fwd primers (Table 1 ). The resulting $\mathrm{pMK}_{-} a p f a_{\mathrm{s}}-\mathrm{ACP}_{\mathrm{m}}$-vacJ construct was transformed into E. coli Stellar competent cells (Clontech Laboratories, Mountain View, CA, USA) according to the In-Fusion protocol, with selection of recombinant clones on brain heart infusion (BHI) plates supplemented with $75 \mu \mathrm{g} \mathrm{m}^{-1}$ kanamycin. Positive clones were analyzed by PCR and sequencing to verify the acquisition of the vector and the presence of the correct recombinant ORF. The $\mathrm{pMK}$ apfa $a_{\mathrm{s}}-\mathrm{ACP}_{\mathrm{m}}$-vacJ construct was extracted and purified using a miniprep kit (Qiagen, Hilden, Germany) and subsequently transformed into E. coli electrocompetent S17-1 $\lambda$ pir cells, prepared and transformed as described in Reference [48]. Positive S17-1 $\lambda$ pir clones were then used for transferring the $\mathrm{pMK} \_a p f a_{\mathrm{s}}-\mathrm{ACP}_{\mathrm{m}}-v a c J$ vector into $A$. pleuropneumoniae wt cells by conjugation, following the protocol described in Reference [49]. A. pleuropneumoniae $\mathrm{pMK} \_a p f a_{\mathrm{s}}-\mathrm{ACP}_{\mathrm{m}}-\mathrm{vacJ}$ clones were analyzed by PCR to verify the acquisition of the recombinant $\mathrm{pMK} \_a p f a_{\mathrm{s}}-\mathrm{ACP}_{\mathrm{m}}-$ vacj vector.

\subsection{Outer Membrane Isolation}

A. pleuropneumoniae serotype 8 MIDG2331 [50] wt and the $\mathrm{pMK} a a p f a_{\mathrm{s}}-\mathrm{ACP}_{\mathrm{m}}-\mathrm{vacJ}$ transformed strain were inoculated into $5 \mathrm{~mL}$ of BHI broth containing $20 \mathrm{mg} \mathrm{L}^{-1} \beta-\mathrm{NAD}$ ( $\beta$ nicotinamide adenine dinucleotide) (Merck Millipore, Burlington, Massachusetts, United States) in sterile $50 \mathrm{~mL}$ centrifuge tubes. Next, the cultures were incubated overnight $(\geq 16 \mathrm{~h})$ at $37^{\circ} \mathrm{C}$ with agitation $(200 \mathrm{rpm})$ in an aerobic atmosphere. $10 \mu \mathrm{L}$ of the cultures were inoculated into $50 \mathrm{~mL}$ fresh BHI broth containing $20 \mathrm{mg} \mathrm{L}^{-1} \beta$-NAD in $250 \mathrm{~mL}$ Erlenmeyer conical flasks. After incubation for $12-14 \mathrm{~h}$, the cultures were adjusted to an $\mathrm{OD}_{600}$ of 1 and centrifuged for $1 \mathrm{~h}$ at $2600 \times g$. The pelleted cells were then resuspended, washed once in $10 \mathrm{mmol} \mathrm{L}{ }^{-1} \mathrm{HEPES}$ of $\mathrm{pH} 7.4$ and stored at $-80^{\circ} \mathrm{C}$. After thawing, $15 \mu \mathrm{lof} 1 \mathrm{mmol} \mathrm{L}-1$ 
$\mathrm{MgCl}_{2}$ and standard units of DNAse I and lysozyme were added to the cells. The cells were lysed using a bead beater (Precellys Minilys, Bertin Technologies, Montigny-le-Bretonneux, France) (3 cycles of $3200 \times g$ for $3 \mathrm{~min}$ ). The lysate was then centrifuged for $5 \mathrm{~min}$ at $29,000 \times \mathrm{g}$ at $4{ }^{\circ} \mathrm{C}$ in a tabletop centrifuge to remove cell debris. The supernatant was moved to a fresh $2 \mathrm{~mL}$ tube and centrifuged for $1 \mathrm{~h}$ at $29,000 \times g$ at $4{ }^{\circ} \mathrm{C}$ to collect membranes. The pelleted membranes were resuspended thoroughly in $0.2 \mathrm{~mL} 10 \mathrm{mmol} \mathrm{L}^{-1}$ HEPES of $\mathrm{pH}$ 7.4. The inner membrane was then solubilized with $0.2 \mathrm{~mL}$ of $0.2 \%$ lauroyl sarcosine in $10 \mathrm{mmol} \mathrm{L}^{-1} \mathrm{HEPES}$ ( $\mathrm{pH} \mathrm{7.4)}$ ) for $30 \mathrm{~min}$ at room temperature. Following this, the solution was centrifuged for $1 \mathrm{~h}$ at $29,000 \times g$ at $4{ }^{\circ} \mathrm{C}$ to pellet the OM. The pellet was then washed once with $10 \mathrm{mmol} \mathrm{L}^{-1}$ HEPES ( $\mathrm{pH}$ 7.4) and resuspended in $30 \mu \mathrm{L}$ of $10 \mathrm{mmol} \mathrm{L}^{-1}$ HEPES.

\subsection{SDS-PAGE}

For SDS-PAGE, a standard protocol was applied. $10 \mu \mathrm{L}$ of sample buffer, Laemmli, $2 \mathrm{x}$ concentrate loading buffer and $10 \mu \mathrm{L}$ of supernatant and OM fractions of A. pleuropneumoniae serotype 8 MIDG2331 wt and pMK_apfa $a_{\mathrm{s}}-\mathrm{ACP}_{\mathrm{m}}$-vacJ strain were loaded onto 4-20\% gradient SDS-Page gel (Bio-Rad). The Precision Plus Protein ${ }^{\mathrm{TM}}$ Dual Color Standard (Bio-Rad, Hercules, CA, USA) was included for molecular weight estimation. The proteins were run at $150 \mathrm{~V}$ for $45 \mathrm{~min}$ and then stained with Coomassie Blue. Imaging was performed using a Gel doc ${ }^{\mathrm{TM}} \mathrm{XR}+$ device with Image $\mathrm{Lab}^{\mathrm{TM}}$ software (Bio-Rad, Hercules, CA, USA).

\subsection{Liquid Chromatography-Mass Spectrometry}

Protein concentrations of inner and $\mathrm{OM}$ fractions were determined by Pierce ${ }^{\mathrm{TM}}$ bicinchoninic acid (BCA) Protein Assay Kit (ThermoFisher Scientific, Waltham, MA, USA). For liquid chromatography-mass spectrometry (LC/MS) analysis, all samples were adjusted to the protein concentration of $0.4 \mathrm{mg} \mathrm{mL}^{-1}$ in $10 \mathrm{mmol} \mathrm{L}^{-1}$ HEPES of $\mathrm{pH}$ 7.4. The samples were digested with $10 \mu \mathrm{g}$ trypsin (sequencing grade) (Promega, Madison, WI, USA) overnight at $37^{\circ} \mathrm{C}$. The digestion was

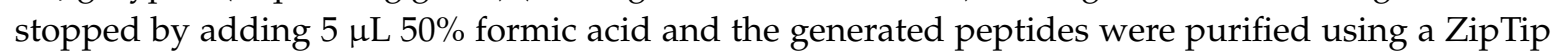
C18 (Merck Millipore, Burlington, MA, USA) according to the manufacturer's instructions and dried using a Speed Vac concentrator Plus (Eppendorf, Hamburg, Germany). The tryptic peptides were analyzed using an Ultimate 3000 nano-UHPLC system connected to a Q Exactive mass spectrometer (ThermoFisher Scientific, Waltham, MA, USA) equipped with a nano electrospray ion source.

\subsection{Protein Identification by Scaffold Viewer}

LC/MS data were analyzed using Scaffold ${ }^{\mathrm{TM}}$ (Scaffold_4.8.9, Proteome Software Inc., Portland, Oregon, United States). The threshold for peptide identification was set at $>95.0 \%$ probability (Peptide Prophet algorithm) [51] with Scaffold delta-mass correction. The threshold for protein identification was set at $>99.9 \%$ probability in addition to at least one identified peptide. Protein probabilities were assigned by the Protein Prophet algorithm [52]. Proteins that contained similar peptides and which could not be differentiated based on tandem mass spectrometry (MS/MS) analysis alone were grouped to satisfy the principles of parsimony.

\subsection{Flow Cytometry}

Inoculation loops containing stored $\left(-80^{\circ} \mathrm{C}\right)$ A. pleuropneumoniae serotype 8 MIDG2331 [50] wt and the $\mathrm{pMK} \_a p f a_{\mathrm{s}}-\mathrm{ACP}_{\mathrm{m}}-v a c J$ plasmid containing strain were inoculated into $5 \mathrm{~mL}$ of BHI broth containing $20 \mathrm{mg} \mathrm{L}^{-1} \beta$-NAD in sterile $50 \mathrm{~mL}$ centrifuge tubes. Next, the cultures were incubated overnight $(\geq 16 \mathrm{~h})$ at $37^{\circ} \mathrm{C}$ with agitation $(200 \mathrm{rpm})$ in an aerobic atmosphere. $10 \mu \mathrm{L}$ of the cultures were inoculated in $50 \mathrm{~mL}$ fresh BHI broth containing $20 \mathrm{mg} \mathrm{L}^{-1} \beta$-NAD in $250 \mathrm{~mL}$ Erlenmeyer conical flasks. After incubation for $12-14 \mathrm{~h}$, the $\mathrm{OD}_{600}$ of the cultures were adjusted to 0.1 . Cells from $500 \mu \mathrm{L}$ of the $\mathrm{OD}_{600}$ adjusted cultures were harvested $(5000 \times g, 4 \mathrm{~min})$ and re-suspended in $100 \mu \mathrm{l}$ of a staining solution. For the preparation of the staining solution, $10^{-2} \mathrm{~mol} \mathrm{~L}^{-1} \mathrm{MgCl}_{2}, 0.625 \mathrm{nmol} \mathrm{L}^{-1} \mathrm{ACP}$ synthase (NEB, Ipswich, MA, USA) and $0.25 \mathrm{nmol} \mathrm{L}^{-1}$ fluorescent CoA 488 (NEB, Ipswich, MA, USA) 
were added in BHI broth. Incubation was performed in a $1 \mathrm{~mL}$ Eppendorf tube in heating block at $37^{\circ} \mathrm{C}$ for $1 \mathrm{~h}$. The stained cells were harvested (5000 $\times g, 4 \mathrm{~min}$ ) and re-suspended in $200 \mu \mathrm{L}$ of sterile filtered (0.22 $\mu \mathrm{m}$ sterile filters, Sartorius, Göttingen, Germany) Dulbecco's phosphate-buffered saline (ThermoFisher Scientific, Waltham, MA, USA) and analyzed by flow cytometry (BD Accuri ${ }^{\circledR}$ C6, BD Biosciences, San Jose, CA, USA). Following acquisition, the data obtained were analyzed using the FlowJo V10 software (BD Biosciences, San Jose, CA, USA). Three independent experiments were performed. For each data set, the statistical difference between the mean green fluorescence values of wt and pMK_apfas-ACPm-vacJ strains was determined by t-test $(p<0.01)$.

\subsection{Fluorescence Microscopy}

Cultures of $A$. pleuropneumoniae serotype 8 MIDG2331 wt and pMK_apfa $a_{\mathrm{s}}-\mathrm{ACP}_{\mathrm{m}}$-vacJ strain were prepared as described for flow cytometry. After staining, the cells were harvested $(5000 \times g, 4 \mathrm{~min})$ and re-suspended in $50 \mu \mathrm{l}$ of filtered $(0.22 \mu \mathrm{m}$ sterile filters) Dulbecco's phosphate-buffered saline (\#141900, ThermoFisher Scientific, Waltham, MA, USA) and analyzed with fluorescence microscopy (Leica DM5000B, Leica Microsystems, Wetzlar, Germany). For the acquisition of images, phase contrast microscopy with 100× magnification and an oil-immersion objective lens were used. For fluorescence imaging, filter cube I3 with band pass 450-490 nm excitation filter, $510 \mathrm{~nm}$ dichromatic mirror and long pass 515 suppression filter were used. The cell cultures were mixed in a 1:1 ratio with 50\% sterile glycerol on the glass slides just before the microscopy analysis in order to reduce the mobility of the cells for the acquisition of images. Three independent experiments were performed.

\section{Conclusions}

These results represent a valid proof of concept indicating that $\mathrm{ApfA}_{\mathrm{S}}$ could be used as a fusion partner to direct translocation and exposure of small proteins on A. pleuropneumoniae OM. This would ideally result in the generation of recombinant strains which, once inoculated in the host as part of an immunization regime, could elicit a lasting humoral response against the antigens selected for ApfA $\mathrm{A}_{\mathrm{s}}$-mediated OM enrichment. Additionally, the cross-species conservation of some $\mathrm{Apf}_{\mathrm{s}}$ domains leads us to speculate that the expression platform described in this study could be used for the construction of recombinant chimeras aimed at antigen enrichment of the OM of other Gram-negative species of interest. Nonetheless, all these assumptions are preliminary in nature and further testing will be necessary to verify these hypotheses.

Supplementary Materials: The following are available online at http://www.mdpi.com/2076-0817/9/12/1014/s1, Table S1: Extended Mass Spectrometry data table.

Author Contributions: Design of study, A.M.B., F.A. In silico analysis, F.A. Plasmid engineering and cloning, F.A. Fluorescence microscopy and flow cytometry analysis, A.O., F.A. Membrane fractionation, mass spectrometry and protein analysis, A.W., F.A., H.C.W.-L. All authors have read and agreed to the published version of the manuscript.

Funding: The project was partly funded by The University of Copenhagen, Center for Control of Antimicrobial Resistance (UC-Care) and the Center for Research in Pig Production and Health (CPH Pig) at University of Copenhagen.

Acknowledgments: We would like to thank Janine T. Bossé and Paul Langford (Imperial College London, UK) for providing the pMK-express vector used in this study. Imaging data were collected at the Center for Advanced Bioimaging (CAB) Denmark, University of Copenhagen (http://cab.ku.dk/). The project was partly funded by The University of Copenhagen, Center for Control of Antimicrobial Resistance (UC-Care) and the Center for Research in Pig Production and Health (CPH Pig) at University of Copenhagen. We would like to thank the Proteomic Unit at the University of Oslo for performing the liquid chromatography-mass spectrometry analysis. Finally, special thanks to Sarah Finke at University of Oslo for performing an additional run of the SDS-page analysis.

Conflicts of Interest: The authors declare no conflict of interest.

\section{References}

1. Rosano, G.L.; Ceccarelli, E.A. Recombinant protein expression in Escherichia coli: Advances and challenges. Front. Microbiol. 2014, 5, 172. [CrossRef] 
2. Khan, S.; Ullah, M.W.; Siddique, R.; Nabi, G.; Manan, S.; Yousaf, M.; Hou, H. Role of Recombinant DNA Technology to Improve Life. Int. J. Genom. 2016, 2016, 2405954. [CrossRef]

3. Ellis, R.W.; Brodeur, B.R. New Bacterial Vaccines; Springer: Boston, MA, USA, 2003; ISBN 978-1-4613-4902-0.

4. Flower, D.R.; Perrie, Y. Immunomic Discovery of Adjuvants and Candidate Subunit Vaccines; Springer: New York, NY, USA, 2013; ISBN 9781461450702.

5. Tomar, N.; De, R.K. Immunoinformatics: A brief review. Methods Mol. Biol. 2014, 1184, 23-55.

6. Sette, A. Reverse Vaccinology: Developing Vaccines in the Era of Genomics. Immunity 2010, 33, 530-541. [CrossRef]

7. Yu, N.Y.; Wagner, J.R.; Laird, M.R.; Melli, G.; Rey, S.; Lo, R.; Dao, P.; Cenk Sahinalp, S.; Ester, M.; Foster, L.J.; et al. PSORTb 3.0: Improved protein subcellular localization prediction with refined localization subcategories and predictive capabilities for all prokaryotes. Bioinformatics 2010, 26, 1608-1615. [CrossRef]

8. Anderson, R.J.; Guru, S.; Weeratna, R.; Makinen, S.; Falconer, D.J.; Sheppard, N.C.; Lang, S.; Chang, B.; Goenaga, A.L.; Green, B.A.; et al. In vivo screen of genetically conserved Streptococcus pneumoniae proteins for protective immunogenicity. Vaccine 2016, 34, 6292-6300. [CrossRef]

9. Lundberg, U.; Senn, B.M.; Schuler, W.; Meinke, A.; Hanner, M. Identification and characterization of antigens as vaccine candidates against Klebsiella pneumoniae. Hum. Vaccines Immunother. 2013, 9, 497-505. [CrossRef]

10. Van Regenmortel, M.H.V. Structure-based reverse vaccinology failed in the case of HIV because it disregarded accepted immunological theory. Int. J. Mol. Sci. 2016, 17, 1591. [CrossRef]

11. Donati, C.; Rappuoli, R. Reverse vaccinology in the 21st century: Improvements over the original design. Ann. N. Y. Acad. Sci. 2013, 1285, 115-132. [CrossRef]

12. Gomes, A.; Byregowda, S.; Veeregowda, B.; Balamurugan, V. An Overview of Heterologous Expression Host Systems for the Production of Recombinant Proteins. Recomb. Gene Expr. 2016, 4, 15-51. [CrossRef]

13. Bilgimol, J.C.; Suthakaran, P.; Sankaranarayanan, S.; Musti, M.; Kalimuthu, S.; Ganesan, M.; Sadananda, R.M. An overview of the parameters for recombinant protein expression in Escherichia coli. Cell Sci. Ther. 2015, 6, 1-7. [CrossRef]

14. Jia, B.; Jeon, C.O. High-throughput recombinant protein expression in Escherichia coli: Current status and future perspectives. Open Biol. 2016, 6, 1-17. [CrossRef]

15. Thanassi, D.G.; Hultgren, S.J. Multiple pathways allow protein secretion across the bacterial outer membrane. Curr. Opin. Cell Biol. 2000, 12, 420-430. [CrossRef]

16. Filloux, A. Secretion signal and protein targeting in Bacteria: A biological puzzle. J. Bacteriol. 2010, 192, 3847-3849. [CrossRef]

17. Balbás, P.; Lorence, A. Recombinant Gene Expression Reviews and Protocols; Springer Science \& Business Media: Berlin/Heidelberg, Germany, 2004; Volume 267, ISBN 1592597742.

18. Terpe, K. Overview of tag protein fusions: From molecular and biochemical fundamentals to commercial systems. Appl. Microbiol. Biotechnol. 2003, 60, 523-533. [CrossRef]

19. Lotze, J.; Reinhardt, U.; Seitz, O.; Beck-Sickinger, A.G. Peptide-tags for site-specific protein labelling in vitro and in vivo. Mol. BioSyst. 2016, 12, 1731-1745. [CrossRef]

20. Yano, Y.; Matsuzaki, K. Tag-probe labeling methods for live-cell imaging of membrane proteins. Biochim. Biophys. Acta Biomembr. 2009, 1788, 2124-2131. [CrossRef]

21. Botos, I.; Noinaj, N.; Buchanan, S.K. Insertion of proteins and lipopolysaccharide into the bacterial outer membrane. Philos. Trans. R. Soc. B Biol. Sci. 2017, 372, 20160224. [CrossRef]

22. Gu, Y.; Li, H.; Dong, H.; Zeng, Y.; Zhang, Z.; Paterson, N.G.; Stansfeld, P.J.; Wang, Z.; Zhang, Y.; Wang, W.; et al. Structural basis of outer membrane protein insertion by the BAM complex. Nature 2016, 531, 64-69. [CrossRef]

23. Cho, B.K.; Knight, E.M.; Palsson, B. PCR-based tandem epitope tagging system for Escherichia coli genome engineering. Biotechniques 2006, 40, 67-72. [CrossRef]

24. Bauler, L.D.; Hackstadt, T. Expression and Targeting of secreted proteins from Chlamydia trachomatis. J. Bacteriol. 2014, 196, 1325-1334. [CrossRef]

25. Bossé, J.T.; Janson, H.; Sheehan, B.J.; Beddek, A.J.; Rycroft, A.N.; Simon Kroll, J.; Langford, P.R. Actinobacillus pleuropneumoniae: Pathobiology and pathogenesis of infection. Microbes Infect. 2002, 4, 225-235. [CrossRef]

26. Ramjeet, M.; Deslandes, V.; Gouré, J.; Jacques, M. Actinobacillus pleuropneumoniae vaccines: From bacterins to new insights into vaccination strategies. Anim. Health Res. Rev. 2008, 9, 25-45. [CrossRef] 
27. Sjölund, M.; Wallgren, P. Field experience with two different vaccination strategies aiming to control infections with Actinobacillus pleuropneumoniae in a fattening pig herd. Acta Vet. Scand. 2010, 52, 23. [CrossRef]

28. Sadilkova, L.; Nepereny, J.; Vrzal, V.; Sebo, P.; Osicka, R. Type IV fimbrial subunit protein ApfA contributes to protection against porcine pleuropneumonia. Vet. Res. 2012, 43, 2. [CrossRef]

29. Zhou, Y.; Li, L.; Chen, Z.; Yuan, H.; Chen, H.; Zhou, R. Adhesion Protein ApfA of Actinobacillus pleuropneumoniae Is Required for Pathogenesis and Is a Potential Target for Vaccine Development. Clin. Vaccine Immunol. 2013, 20, 287-294. [CrossRef]

30. Shao, M.; Wang, Y.; Wang, C.; Guo, Y.; Peng, Y.; Liu, J.; Li, G.; Liu, H.; Liu, S. Evaluation of multicomponent recombinant vaccines against Actinobacillus pleuropneumoniae in mice. Acta Vet. Scand. 2010, 52, 52. [CrossRef]

31. Deslandes, V.; Denicourt, M.; Girard, C.; Harel, J.; Nash, J.H.E.; Jacques, M. Transcriptional profiling of Actinobacillus pleuropneumoniae during the acute phase of a natural infection in pigs. BMC Genom. 2010, 11, 98. [CrossRef]

32. Antenucci, F.; Fougeroux, C.; Bossé, J.T.; Magnowska, Z.; Roesch, C.; Langford, P.; Holst, P.J.; Bojesen, A.M. Identification and characterization of serovar-independent immunogens in Actinobacillus pleuropneumoniae. Vet. Res. 2017, 48, 74. [CrossRef]

33. Antenucci, F.; Fougeroux, C.; Deeney, A.; Ørskov, C.; Rycroft, A.; Holst, P.J.; Bojesen, A.M. In vivo testing of novel vaccine prototypes against Actinobacillus pleuropneumoniae. Vet. Res. 2018, 49. [CrossRef]

34. Tozakidis, I.E.P.; Sichwart, S.; Jose, J. Going beyond E. coli: Autotransporter based surface display on alternative host organisms. New Biotechnol. 2015, 32, 644-650. [CrossRef] [PubMed]

35. Hildegard, E.; Minh, D.B.; Schellack, C.; Nagy, E.; Meinke, A. Bacterial phage receptors, versatile tools for display of polypeptides on the cell surface. J. Bacteriol. 2001, 183, 6924-6935. [CrossRef]

36. Chmielewski, M.; Kuehle, J.; Chrobok, D.; Riet, N.; Hallek, M.; Abken, H. FimH-based display of functional eukaryotic proteins on bacteria surfaces. Sci. Rep. 2019, 9, 1-10. [CrossRef] [PubMed]

37. George, N.; Pick, H.; Vogel, H.; Johnsson, N.; Johnsson, K. Specific labeling of cell surface proteins with chemically diverse compounds. J. Am. Chem. Soc. 2004, 126, 8896-8897. [CrossRef] [PubMed]

38. McAllister, K.A.; Peery, R.B.; Zhao, G. Acyl carrier protein synthases from gram-negative, gram-positive, and atypical bacterial species: Biochemical and structural properties and physiological implications. J. Bacteriol. 2006, 188, 4737-4748. [CrossRef] [PubMed]

39. Zhou, Z.; Koglin, A.; Wang, Y.; McMahon, A.P.; Walsh, C.T. An eight residue fragment of an acyl carrier protein suffices for post-translational introduction of fluorescent pantetheinyl arms in protein modification in vitro and in vivo. J. Am. Chem. Soc. 2008, 130, 9925-9930. [CrossRef]

40. Roier, S.; Zingl, F.G.; Cakar, F.; Durakovic, S.; Kohl, P.; Eichmann, T.O.; Klug, L.; Gadermaier, B.; Weinzerl, K.; Prassl, R.; et al. A novel mechanism for the biogenesis of outer membrane vesicles in Gram-negative bacteria. Nat. Commun. 2016, 7, 10515. [CrossRef]

41. Kolberg, K.; Puettmann, C.; Pardo, A.; Fitting, J.; Barth, S. SNAP-Tag Technology: A General Introduction. Curr. Pharm. Des. 2013, 19, 5406-5413. [CrossRef]

42. Smith, S.M. Strategies for the purification of membrane proteins. Methods Mol. Biol. 2011, 681, 485-496. [CrossRef]

43. Thomas, P.D.; Campbell, M.J.; Kejariwal, A.; Mi, H.; Karlak, B.; Daverman, R.; Diemer, K.; Muruganujan, A.; Narechania, A. PANTHER: A library of protein families and subfamilies indexed by function. Genome Res. 2003, 13, 2129-2141. [CrossRef]

44. Mi, H.; Dong, Q.; Muruganujan, A.; Gaudet, P.; Lewis, S.; Thomas, P.D. PANTHER version 7: Improved phylogenetic trees, orthologs and collaboration with the Gene Ontology Consortium. Nucleic Acids Res. 2009, 38. [CrossRef]

45. Käll, L.; Krogh, A.; Sonnhammer, E.L.L. A combined transmembrane topology and signal peptide prediction method. J. Mol. Biol. 2004, 338, 1027-1036. [CrossRef]

46. Roy, A.; Kucukural, A.; Zhang, Y. I-TASSER: A unified platform for automated protein structure and function prediction. Nat. Protoc. 2010, 5, 725-738. [CrossRef] [PubMed]

47. Agarwala, R.; Barrett, T.; Beck, J.; Benson, D.A.; Bollin, C.; Bolton, E.; Bourexis, D.; Brister, J.R.; Bryant, S.H.; Canese, K.; et al. Database Resources of the National Center for Biotechnology Information. Nucleic Acids Res. 2017, 44, D7-D19. [CrossRef]

48. Gonzales, M.F.; Brooks, T.; Pukatzki, S.U.; Provenzano, D. Rapid protocol for preparation of electrocompetent Escherichia coli and Vibrio cholerae. J. Vis. Exp. 2013, 50684, e50684. [CrossRef] 
49. Bossé, J.T.; Durham, A.L.; Rycroft, A.N.; Kroll, J.S.; Langford, P.R. New Plasmid Tools for Genetic Analysis of Actinobacillus pleuropneumoniae and Other Pasteurellaceae. Appl. Environ. Microbiol. 2009, 75, 6124-6131. [CrossRef]

50. Bossé, J.T.; Chaudhuri, R.R.; Li, Y.; Leanse, L.G.; Fernandez Crespo, R.; Coupland, P.; Holden, M.T.G.; Bazzolli, D.M.; Maskell, D.J.; Tucker, A.W.; et al. Complete Genome Sequence of MIDG2331, a Genetically Tractable Serovar 8 Clinical Isolate of Actinobacillus pleuropneumoniae. Genome Announc. 2016, 4, e1667-15. [CrossRef]

51. Keller, A.; Nesvizhskii, A.I.; Kolker, E.; Aebersold, R. Empirical statistical model to estimate the accuracy of peptide identifications made by MS/MS and database search. Anal. Chem. 2002, 74, 5383-5392. [CrossRef]

52. Nesvizhskii, A.I.; Keller, A.; Kolker, E.; Aebersold, R. A statistical model for identifying proteins by tandem mass spectrometry. Anal. Chem. 2003, 75, 4646-4658. [CrossRef]

Publisher's Note: MDPI stays neutral with regard to jurisdictional claims in published maps and institutional affiliations.

(C) 2020 by the authors. Licensee MDPI, Basel, Switzerland. This article is an open access article distributed under the terms and conditions of the Creative Commons Attribution (CC BY) license (http://creativecommons.org/licenses/by/4.0/). 